Publisher: African Networks on Ethnomedicines

Web page: /http://journals.sfu.ca/africanem/index.php/ajtcam/index

http://dx.doi.org/10.4314/ajtcam.v9i3.6

\title{
ANTI-FERTILITY EFFECTS OF DIFFERENT FRACTIONS OF ANETHUM GRAVEOLENS L. EXTRACTS ON FEMALE RATS
}

\author{
Monsefi Malihezaman*, Masoudi Mojaba*, Hosseini Elham*, Gramifar Farnaz*, Miri Ramin** \\ *Biology Department, College of Sciences, Shiraz University, Shiraz-Iran \\ ** Medicinal \& Natural Products Chemistry Research Centre, Shiraz University of Medical Sciences, \\ Shiraz-Iran \\ *Email: monsefi@susc.ac.ir
}

\begin{abstract}
Our previous studies showed the effects of aqueous and ethanol extracts of Anethum graveolens L. (dill) on female infertility. In the present study we investigated whether different fractions of this herb extract can cause infertility in rats. Female rats were divided into the control groups, the groups receiving either a low $(0.5 \mathrm{~g} / \mathrm{kg}))$ or a high dose $(5 \mathrm{~g} / \mathrm{kg})$ of water, N-butanol, chloroform and ether fractions of the aqueous plant extract, and the groups receiving either a low $(0.045$ $\mathrm{g} / \mathrm{kg})$ or a high dose $(0.45 \mathrm{~g} / \mathrm{kg})$ of the same fractions of ethanol extract. The mentioned doses were gavaged in $1 \mathrm{~mL}$ for 10 days. Vaginal smears were prepared daily. Estradiol and progesterone levels were measured. The left oviduct and ovary were removed, their tissue subsequently being prepared in form of histology slides and stained using haematoxylin-eosin and Masson's trichrome. Female rats assigned to each group were mated with males; after that, crown-rump lengths and weights of newborn rats were measured. Results showed that each fraction produced some changes such as hormonal level reduction (chloroform fraction), diestrus phase prolongation and infertility (water fraction), and increase in pregnancy duration (chloroform and ether fractions). We concluded that each fraction comprises only some of the mentioned components and therefore recommended the usage of crude extract, especially the aqueous one, in case infertility aims to be induced.
\end{abstract}

Key words: Anethum graveolens; female reproductive system; fractions; infertility.

\section{Introduction}

Population growth control is very important in many countries; therefore, developing family-planning programs has become fundamental. Many steroidal and non-steroidal compounds have been used as contraceptive and anti-ovulatory agents so as to control fertility. Although these drugs act as potent anti-fertility agents, they are not devoid of side effects. The major side effects are adverse gastrointestinal effects, severe and painful uterine contractions, long-term menstrual cycle irregularities, as well as breast and other cancers. Hence, the search for new potent anti-fertility compounds with minimal side effects is in progress.

Anethum graveolens L. or dill is a member of the Umbeliferae family and has been reported to exhibit antibacterial (Delaquis et al., 1993; Singh et al., 2001; Lopez et al., 2005), anti-proliferative (Nakano et al., 1998) and antioxidant effects (Satyanarayana et al., 2004). According to the traditional medicine, dill increases mother's milk production and promotes menstruation. High doses of dill have been reported to decrease sexual activity and spermatogenesis in men (Duke, 2002; Weiss, 2001). Our previous studies on dill seed aqueous and ethanol extracts showed that dill extract increases plasma progesterone concentration and the duration of the diestrus phase of the oestrous cycle (Monsefi et al., 2006a). These results suggested that dill can be used as either a regulatory agent in women having irregular periods or as an anti-fertility agent. The ultra-structural study of corpus luteum of these animals revealed smooth endoplasmic reticulum (SER), rough endoplasmic reticulum (RER), and mitochondria increase in granulosa lutein cells, which indicates a more pronounced steroidal synthesis. These changes are considered to be the reason for the progesterone levels to be high (Monsefi et al., 2006b).

Studying different fractions of a medicinal plant helps us understand which extract components act on target organs. Therefore, this study was designed to investigate the anti-fertility properties of different fractions of A. graveolens extract and their effects in female rats.

\section{Materials and Methods Preparation of fractions}

Dill seeds were separated from other seeds using a stereomicroscope. The identity of the seeds was confirmed by the Department of Biology, Shiraz University, Shiraz, Iran. A voucher specimen (1015) was kept at the Herbarium of the Department of Biology, Shiraz University. Seeds were then powdered and subjected to extraction. One hundred $g$ of the powder and $300 \mathrm{~mL}$ of $80 \%$-ethanol (for ethanol extract), as well as $100 \mathrm{~g}$ of the powder and $300 \mathrm{~mL}$ of distilled water (for aqueous extract), were percolated for 24 hours. Subsequently, the mixtures were filtered and concentrated under a reduced pressure using a rotary evaporator. The yields $(\mathrm{w} / \mathrm{w})$ of the aqueous and ethanol extracts were $8.2 \%(\mathrm{~g} / \mathrm{g})$ and $4.5 \%(\mathrm{~g} / \mathrm{g})$, 
Publisher: African Networks on Ethnomedicines

Web page: /http://journals.sfu.ca/africanem/index.php/ajtcam/index

http://dx.doi.org/10.4314/ajtcam.v9i3.6

respectively. In the subsequent course, $20 \mathrm{~g}$ of the aqueous extract and $40 \mathrm{~g}$ of the ethanol extract were independently rinsed three times with ether, N-butanol, chloroform and water at the room temperature. The oily liquids were evaporated to dryness under vacuum conditions. The yields $(\mathrm{w} / \mathrm{w})$ of ether, chloroform, N-butanol and water fractions of the aqueous extract were $2.5 \%(\mathrm{~g} / \mathrm{g}), 0.5 \%(\mathrm{~g} / \mathrm{g}), 4.75 \%(\mathrm{~g} / \mathrm{g})$ and $77.5 \%(\mathrm{~g} / \mathrm{g})$, respectively, while the yields $(\mathrm{w} / \mathrm{w})$ of four fractions of ethanol extract were $70 \%(\mathrm{~g} / \mathrm{g}), 0.25 \%(\mathrm{~g} / \mathrm{g}), 5.25 \%(\mathrm{~g} / \mathrm{g})$ and $11.3 \%(\mathrm{~g} / \mathrm{g})$, respectively.

\section{Animals and fraction administrations}

Female Wistar rats weighing 150-200 g were obtained from the animal house of the Razi Institute of Shiraz. The animals had been adapted to the laboratory conditions for two weeks before the beginning of the experiments and vaginal smears were examined daily so as to enable for the selection of rats with normal oestrous cycles. Animals were maintained at the controlled temperature $\left(22-24{ }^{\circ} \mathrm{C}\right)$ and exposed to12-hour alternating light-dark cycles. Rats had free access to food and tap water. Animals were weighed before and after the experiments. Principles of laboratory care established by the National Institute of Health (NIH Publication, No. 85-23, 1985 revision) were followed at all times. Female rats with regular oestrous cycles were divided into different groups ( 6 animals in each group). Eight animal groups received either a low $(0.5 \mathrm{~g} / \mathrm{kg})$ or a high dose $(5 \mathrm{~g} / \mathrm{kg})$ of N-butanol, water, chloroform and ether fractions of the aqueous extract, while another 8 animal groups received either a low $(0.045 \mathrm{~g} / \mathrm{kg})$ or a high dose $(0.45 \mathrm{~g} / \mathrm{kg})$ of 4 ethanol extract fractions. High doses of water and ethanol fractions equalled to the maximal non-fatal doses established based on the previous study (Hosseinzadeh et al., 2002). The control animal group was included as well; it received equal volumes of distilled water. The sham group received DMSO as a solvent of the chloroform fraction. The mentioned fraction dose was suspended in $1 \mathrm{~mL}$ of distilled water when it comes to N-butanol, water and ether fractions, and DMSO when it comes to chloroform fraction, and orally administrated by needle gavage for 10 days ( 2 regular oestrous cycles) during the oestrus phase of the oestrous cycle. During the course of the experiments, vaginal smears were prepared in the morning hours (9-10 AM).

\section{Hormonal assay}

In order to determine the variations in plasma concentrations of estradiol and progesterone, after the last administration, while in the oestrus phase, the animals were anesthetized using diethyl ether and taken approximately $4 \mathrm{~mL}$ of their blood by virtue of dorsal aorta puncture. Blood samples were centrifuged for $15 \mathrm{~min}$ at $2000 \mathrm{rpm}$ and the serum was separated. Progesterone concentrations present in the samples were determined using the radioimmunoassay solid phase method, while estradiol concentrations were measured by virtue of ELISA method using Spectria Kit. The measurements took place in the Research Centre of the Nemazee Hospital.

\section{Organ weights}

At the end of the experiment, the rats were sacrificed under deep anaesthesia and their ovaries and uterine tubes were removed and weighed. Standard weights of these organs were calculated as [organ weight (g)/ body weight $(\mathrm{g})] \times 100$.

\section{Histological studies}

The left ovary and the uterine tube of each rat were removed, fixed in 10\%-buffer formalin solution and prepared using routine histological techniques. Samples were dehydrated using alcohol, cleared with xylol, embedded into a paraffin wax, sectioned to $7 \mu \mathrm{m}$ - thickness, and stained with haematoxylin-eosin and Masson's trichrome according to Bancroft and Stevens (1991). Finally, photographs of the prepared slides were taken.

\section{Animal mating}

To evaluate the effect of different fractions of A. graveolens on fertility and growth of the rat newborns, we treated all animal groups (the control, the low- and the high-dose arms) ( 3 in each mating group). After the last administration, at 4.00 PM, female animals from each group were put in a common cage with untreated male rats for mating. At 7 AM next morning, females were checked for vaginal plaque and intra-vaginal sperm presence. After that, vaginal smears were prepared. For each pregnant female rat, the duration of pregnancy and the number of newborns was counted. Finally, crownrump length $(\mathrm{CRL})$ of each rat newborn was measured.

\section{Statistical analysis}

Data obtained from different groups were analyzed using One-way analysis of variance (ANOVA) and Scheffe and Tukey tests. Statistical analysis was performed using SPSS 11.5 software. $\mathrm{P}<0.05$ was considered statistically significant.

\section{Results}


Publisher: African Networks on Ethnomedicines

Web page: /http://journals.sfu.ca/africanem/index.php/ajtcam/index

http://dx.doi.org/10.4314/ajtcam.v9i3.6

Different fractions of A. graveolens extracts did not have any significant effect on body weight and reproductive organs. Therefore, dill components seem to be safe and have no toxic effect on body growth (Table 1). There were no statistically significant differences in the amount of serum progesterone between the experimental, the control and the sham groups, but, as compared to the control and the sham groups in the chloroform fractions-treated group serum estradiol concentrations were significantly decreased (Table 2).

In high dose groups receiving the water fraction of the aqueous plant extract, the duration of the diestrus phase of the oestrous cycle was significantly prolonged as compared to the control group. As for other fractions and other animal groups, the effects on the duration of the estrus phases and oestrous cycle were insignificant (Table 3).

Table 1: The effects of different fractions of Anethum graveolens L. on body weight and reproductive organs (g) of female rats

\begin{tabular}{lll|ll|ll|ll}
\hline & \multicolumn{2}{l}{ Water fraction } & \multicolumn{2}{l|}{ Ether fraction } & \multicolumn{2}{l|}{ Chloroform fraction } & \multicolumn{2}{l}{ N-butanol fraction } \\
\cline { 2 - 10 } & body & organs & body & organs & body & organs & body & organs \\
\hline CON & $187.02 \pm 43.16$ & $0.34 \pm 0.11$ & $187.02 \pm 43.16$ & $0.36 \pm 0.07$ & $177.21 \pm 41.52$ & $0.47 \pm 0.17$ & $196.26 \pm 29.94$ & $0.28 \pm 0.08$ \\
\hline SHAM & - & - & - & - & $210.83 \pm 82.87$ & $0.35 \pm 0.03$ & - & - \\
\hline LDAE & $196.70 \pm 24.27$ & $0.36 \pm 0.01$ & $194.64 \pm 10.35$ & $0.33 \pm 0.07$ & $153.83 \pm 12.58$ & $0.36 \pm 0.06$ & $193.22 \pm 20.14$ & $0.31 \pm 0.02$ \\
\hline LDEE & $167.54 \pm 20.56$ & $0.36 \pm 0.04$ & $201.60 \pm 5.72$ & $0.34 \pm 0.07$ & $188.26 \pm 16.95$ & $0.47 \pm 0.17$ & $231.80 \pm 21.13$ & $0.38 \pm 0.07$ \\
\hline HDAE & $204.00 \pm 37.72$ & $0.31 \pm 0.15$ & $138.00 \pm 5.07$ & $0.23 \pm 0.05$ & $128.66 \pm 16.95$ & $0.35 \pm 0.04$ & $146.50 \pm 16.46$ & $0.24 \pm 0.02$ \\
\hline HDEE & $169.98 \pm 38.30$ & $0.33 \pm 0.03$ & $168.60 \pm 8.92$ & $0.37 \pm 0.11$ & $131.30 \pm 17.43$ & $0.35 \pm 0.04$ & $118.86 \pm 57.24$ & $0.42 \pm 0.10$ \\
\hline
\end{tabular}

CON: control; LDAE: low dose of aqueous extract; LDEE: low dose of ethanol extract; HDAE: high dose of aqueous extract;

HDEE: high dose of ethanol extract. Values expressed as means \pm S.D.

Table 2: The effects of different fractions of Anethum graveolens L. on blood estradiol and progesterone concentrations $(\mathrm{pg} / \mathrm{mL})$ of female rats

\begin{tabular}{|c|c|c|c|c|c|c|c|c|}
\hline & \multicolumn{2}{|c|}{ Water fraction } & \multicolumn{2}{|c|}{ Ether fraction } & \multicolumn{2}{|c|}{ Chloroform fraction } & \multicolumn{2}{|c|}{ N-butanol Fraction } \\
\hline & estradiol & progesterone & estradiol & $\begin{array}{l}\text { progesteron } \\
\mathrm{e}\end{array}$ & estradiol & progesterone & estradiol & progesterone \\
\hline $\mathrm{CON}$ & $11.98 \pm 4.47$ & $41.89 \pm 8.83$ & $10.74 \pm 5.49$ & $40.61 \pm 10.67$ & $10.09 \pm 4.10$ & $41.74 \pm 8.98$ & $8.48 \pm 8.17$ & $37.70 \pm 17.01$ \\
\hline SHAM & - & - & - & - & $7.85 \pm 0.21$ & $41.38 \pm 8.06$ & - & - \\
\hline LDAE & $11.24 \pm 1.08$ & $44.21 \pm 7.18$ & $14.42 \pm 8.42$ & $37.65 \pm 9.20$ & $2.98 \pm 0.73$ & $40.10 \pm 5.52$ & $7.56 \pm 2.92$ & $36.08 \pm 8.87$ \\
\hline LDEE & $11.22 \pm 2.70$ & $42.29 \pm 4.82$ & $13.12 \pm 2.59$ & $47.13 \pm 9.11$ & $3.92 \pm 1.60$ & $41.56 \pm 9.07$ & $5.64 \pm 2.27$ & $42.46 \pm 10.14$ \\
\hline HDAE & $6.92 \pm 1.61$ & $42.56 \pm 9.54$ & $11.56 \pm 1.09$ & $55.93 \pm 2.34$ & $6.76 \pm 1.59$ & $39.80 \pm 8.96$ & $6.96 \pm 2.28$ & $46.90 \pm 4.75$ \\
\hline HDEE & $7.52 \pm 0.94$ & $49.84 \pm 3.21$ & $16.95 \pm 5.45$ & $32.80 \pm 17.65$ & $3.09 \pm 1.71$ & $35.70 \pm 7.21$ & $7.98 \pm 5.16$ & $44.98 \pm 9.44$ \\
\hline
\end{tabular}

Gray-coloured columns show significant differences from the control and the sham groups $(\mathrm{P}<0.05)$.

CON: control; LDAE: low dose of aqueous extract; LDEE: low dose of ethanol extract; HDAE: high dose of aqueous extract;

HDEE: high dose of ethanol extract. Values are expressed as means \pm S.D.

The experiments in female rats that were fed with different fractions of dill extract and then mated with male rats revealed that the water fraction- and the high dose N-butanol fraction-treated group members could not conceive, as oppose to the controls. The rats treated with the chloroform fraction of the aqueous extract showed a longer duration of pregnancy as compared to the control group. The number of newborns and their weight and CRL were normal and did not significantly differ from the control group (Table 4).

Histological studies did not reveal any changes or pathological disorders in ovarian tissues in terms of presence of a different type of ovarian follicles (granulosa cells and oocytes).Corpus luteum, connective tissue and medullar blood vessels also remained intact.. Uterine tube layers such as epithelium and endometrial, myometrial and perimetrial tubular glands were normal, too (Figures 1 and 2).

\section{Discussion}

Different fractions of A. graveolense seed extract did not have any effect on body weight and reproductive organs, which shows that this herbal extract is safe and does not have any growth-related side effects. Hormonal assay is an adequate method to evaluate the functions of the reproductive system. Chloroform fraction of ethanol extracts and a low dose of the aqueous extract significantly reduced estradiol levels; however, other fractions of A. graveolens seed extract did not change 
Publisher: African Networks on Ethnomedicines

Web page: /http://journals.sfu.ca/africanem/index.php/ajtcam/index

http://dx.doi.org/10.4314/ajtcam.v9i3.6

estradiol and progesterone concentrations. Therefore, after the treatment with this herb, we expected the oestrous cycle to run through its normal proestrus, oestrus and diestrus phases. Normally, rat oestrous cycle lasts for 4-5 days (Austin and Short, 1972). Chloroform fraction changed the estrogenic phases of the oestrous cycle (proestrus and oestrus phases), but these changes were not significant. Also, in all treatment groups the oestrous cycle and its diestrus phase were longer than those of the control and the sham groups, but these changes were not statistically significant. Our previous study showed a

Table 3: The effects of different fractions of Anethum graveolens L. on the duration of different phases of rat estrous cycle (days)

\begin{tabular}{|c|c|c|c|c|c|c|c|c|}
\hline & \multicolumn{4}{|c|}{ Water fraction } & \multicolumn{4}{|c|}{ Ether fraction } \\
\hline & $\begin{array}{l}\text { Oestrous } \\
\text { Cycle }\end{array}$ & $\begin{array}{l}\text { Oestrus } \\
\text { phase }\end{array}$ & $\begin{array}{l}\text { Diestrus } \\
\text { phase }\end{array}$ & $\begin{array}{l}\text { Proestrus } \\
\text { phase }\end{array}$ & $\begin{array}{l}\text { Oestrous } \\
\text { cycle }\end{array}$ & $\begin{array}{l}\text { Oestrus } \\
\text { phase }\end{array}$ & $\begin{array}{l}\text { Diestrus } \\
\text { phase }\end{array}$ & $\begin{array}{l}\text { Proestrus } \\
\text { phase }\end{array}$ \\
\hline $\mathrm{CON}$ & $14.96 \pm 2.27$ & $3.88 \pm 0.68$ & $6.58 \pm 3.03$ & $2.46 \pm 1.61$ & $14.95 \pm 2.27$ & $3.83 \pm 0.96$ & $9.04 \pm 2.67$ & $2.08 \pm 1.66$ \\
\hline LDAE & $15.00 \pm 0.00$ & $4.40 \pm 1.14$ & $8.00 \pm 0.70$ & $2.60 \pm 0.89$ & $13.85 \pm 2.96$ & $4.14 \pm 0.69$ & $6.57 \pm 3.45$ & $3.14 \pm 1.21$ \\
\hline LDEE & $14.20 \pm 0.83$ & $4.20 \pm 0.83$ & $8.00 \pm 2.34$ & $2.00 \pm 1.00$ & $12.85 \pm 1.46$ & $4.57 \pm 1.39$ & $6.29 \pm 1.38$ & $2.00 \pm 0.81$ \\
\hline HDAE & $16.00 \pm 2.34$ & $3.60 \pm 0.97$ & $11.40 \pm 1.67$ & $1.00 \pm 1.41$ & $14.05 \pm 1.91$ & $3.50 \pm 1.91$ & $11.00 \pm 2.58$ & $1.00 \pm 1.15$ \\
\hline \multirow[t]{3}{*}{ HDEE } & $14.60 \pm 1.14$ & $3.20 \pm 0.44$ & $10.20 \pm 2.04$ & $1.20 \pm 1.64$ & $13.28 \pm 0.48$ & $4.57 \pm 0.78$ & $5.57 \pm 1.81$ & $3.14 \pm 0.90$ \\
\hline & \multicolumn{4}{|c|}{ Chloroform fraction } & \multicolumn{4}{|c|}{ N-butanol Fraction } \\
\hline & $\begin{array}{l}\text { Oestrous } \\
\text { Cycle }\end{array}$ & $\begin{array}{l}\text { Oestrus } \\
\text { phase }\end{array}$ & $\begin{array}{l}\text { Diestrus } \\
\text { phase }\end{array}$ & $\begin{array}{l}\text { Proestrus } \\
\text { phase }\end{array}$ & $\begin{array}{l}\text { Oestrous } \\
\text { cycle }\end{array}$ & $\begin{array}{l}\text { Oestrus } \\
\text { phase }\end{array}$ & $\begin{array}{l}\text { Diestrus } \\
\text { phase }\end{array}$ & $\begin{array}{l}\text { Proestrus } \\
\text { Phase }\end{array}$ \\
\hline $\mathrm{CON}$ & $14.96 \pm 2.27$ & $3.83 \pm .096$ & $9.04 \pm 2.67$ & $2.08 \pm 1.66$ & $14.00 \pm 2.23$ & $3.40 \pm 0.54$ & $9.00 \pm 3.16$ & $1.60 \pm 1.14$ \\
\hline SHAM & $15.00 \pm 0.00$ & $4.00 \pm 0.00$ & $13.33 \pm 2.08$ & $2.50 \pm 0.70$ & - & - & - & - \\
\hline LDAE & $17.00 \pm 1.00$ & $2.67 \pm 1.15$ & $8.00 \pm 2.34$ & $1.00 \pm 0.00$ & $12.60 \pm 0.54$ & $3.60 \pm 0.54$ & $7.00 \pm 1.22$ & $2.00 \pm 0.70$ \\
\hline LDEE & $13.60 \pm 2.51$ & $4.00 \pm 0.00$ & $11.33 \pm 2.08$ & $1.60 \pm 0.54$ & $12.40 \pm 1.24$ & $3.20 \pm 0.83$ & $8.02 \pm 2.68$ & $2.00 \pm 1.87$ \\
\hline HDAE & $15.00 \pm 1.73$ & $3.00 \pm 0.00$ & $12.33 \pm 1.52$ & $0.67 \pm 0.57$ & $15.67 \pm 0.04$ & $2.67 \pm 1.15$ & $12.67 \pm 5.50$ & $0.57 \pm 0.23$ \\
\hline HDEE & $15.33 \pm 2.08$ & $2.67 \pm 0.57$ & $8.50 \pm 0.70$ & $0.57 \pm 0.33$ & $12.20 \pm 1.30$ & $3.20 \pm 0.83$ & $9.20 \pm 2.16$ & $0.83 \pm 0.80$ \\
\hline
\end{tabular}

The gray-coloured column shows significant differences with control group $(\mathrm{P}<0.05)$.

CON: control; LDAE: low dose of aqueous extract; LDEE: low dose of ethanol extract; HDAE: high dose of aqueous extract; HDEE: high dose of ethanol extract. Values are expressed as means \pm S.D.

significant increase in duration of the oestrous cycle and its diestrus phase, as well as the increase in plasma progesterone concentrations that occurred after treatment with high doses of aqueous and ethanol extracts of this herb (Monsefi et al., 2006). Within the frame of this study, only the water fraction of high dose aqueous extract (HDAE) showed the same results and significantly prolonged the diestrus phase. Therefore we concluded that, despite of our assumption, different fractions of this herb can not induce prolongation or other changes of the oestrous cycle.

Any alteration in hormonal balance can affect the ovarian tissue including the follicular cells of the ovarian follicles and the granolosa cells of the corpus luteum. On the other hand, histological changes can alter hormonal balance, too. In this research, histological aspects of ovaries and uteruses of all treated group members were normal as compared to the control or the sham groups. We assume that all components of this herb put together can cause changes in female reproductive system (shown in our previous studies authored by Monsefi et al., 2006 a \& b), but the fractions of the herb are not able to produce the expected changes. This herb consists of many components such as d-carvone $(67.60 \%)$, d-limonene $(12 \%)$, dill apiol (7.8\%), trans-dyhedrogen (3.6\%), elemicin (1.8\%), $\alpha$-phellandene $(1.3 \%)$, cis-dihydrocarvone $(0.9 \%)$, cisisoeugenol acetate $(0.8 \%)$, trans-anethole $(0.1 \%)$, sis-anethole $(0.1 \%)$ and low amounts of other components (Evan, 1996). Carvone, limonene and trans-anethole are monoterpens. Dill also contains some flavonoids such as kaempferol and vicenin. Some of these components are hydrophilic or polar, while others are hydrophobic or non-polar. Kaempferol, trans-anethole and limonene exhibit phytoestrogenic properties as well. Kaempferol inhibits the binding of oestrogen to serum alphafetoprotein (AFP). Interactions of flavonoids and AFP affect the availability of oestrogen to oestrogen-responsive cells and moderate the expression and function of oestrogen and progesterone receptors. Kaempferol is dissolved in water, diethylether and ethylacetate fractions (Baker et al. 1998). Limonene is a polar component and is dissolved in water fraction (Takahashi et al., 1998), which is not the case with trans-anethole (Brun, 1990).

The chloroform fraction of the two extracts decreased estradiol concentrations in all treatment groups as compared to the control and the sham groups. It is possible that soluble components of this fraction such as some phytoestrogens caused estraodiol reductions. Phytoestrogens can compete with endogenous oestrogen and bind to enzymes related to estradiole synthesis and metabolism, such as 17b-hydroxysteroid oxidoreductase, aromatase, hydroxysteroid sulphotransferase and steroid sulphatase. Phytoestrogens also induce the synthesis of liver SHBG components, reduce serum estradiol levels, activate the steroid xenobiotic receptor and facilitate both endogenous and exogenous oestrogen deletions (Hung, 2004). Phytoestrogens are structurally and functionally identical to $17-\beta$ oestrole and have shown agonistic and antagonistic effects depending on oestrogen concentration (Adlercreutz et al., 1993; Kurzer and Xiz, 1997).

The results of animal mating revealed that water fractions of both extracts induce infertility, as there were no pregnancies in these groups. Animals treated with these fractions showed normal oestrous cycles and hormonal concentrations. Trans-anethole is one of the components of this herb (Toru et al., 2002). Trans-anethole has been shown to 
Publisher: African Networks on Ethnomedicines

Web page: /http://journals.sfu.ca/africanem/index.php/ajtcam/index

http://dx.doi.org/10.4314/ajtcam.v9i3.6

prevent implantation and exhibit anti-fertility effects in female rats (Dhar, 1995). However, Brun (1990) reported that it is insoluble in water. We assume that other mechanisms are involved in this phenomenon and have therefore investigated glycoconjugate-related oocyte and endometrial epithelial cell changes that are involved in sperm recognition and embryonic implantation (the manuscript is in preparation).

In summary, each fraction produced some alterations such as hormonal level reductions (chloroform fraction), diestrus phase prolongation (water fraction), infertility (water fraction) and increase in duration of pregnancy (chloroform and ether fractions). We did not observe the anticipated alterations that, according to the previous studies, are produced after the crude extract administration; therefore, we presume that each fraction contains only some of the mentioned components. In conclusion, we recommend the use of crude and especially the aqueous extract of this herb for the sake of infertility induction.

Table 4: The effects of different fractions of Anethum graveolens L. on the duration of pregnancy (day), as well as the number, weight $(\mathrm{g})$ and crown-rump length $(\mathrm{mm})$ of the rat newborns

\begin{tabular}{|c|c|c|c|c|c|c|c|c|}
\hline \multicolumn{5}{|c|}{ Water fraction } & \multicolumn{4}{|c|}{ Ether fraction } \\
\hline & $\begin{array}{l}\text { Pregnancy } \\
\text { period }\end{array}$ & $\begin{array}{l}\text { Newborn } \\
\text { number }\end{array}$ & $\begin{array}{l}\text { Newborn } \\
\text { weight }\end{array}$ & $\begin{array}{l}\text { Newborn } \\
\text { CRL }\end{array}$ & $\begin{array}{l}\text { Pregnancy } \\
\text { period }\end{array}$ & $\begin{array}{l}\text { Newborn } \\
\text { number }\end{array}$ & $\begin{array}{l}\text { Newborn } \\
\text { weight }\end{array}$ & $\begin{array}{l}\text { Newborn } \\
\text { CRL }\end{array}$ \\
\hline $\mathrm{CON}$ & $20.67 \pm 0.51$ & $7.71 \pm 3.49$ & $5.83 \pm 0.61$ & $4.83 \pm 0.33$ & $20.75 \pm 1.70$ & $10.00 \pm 0.81$ & $5.25 \pm 0.28$ & $4.95 \pm 0.31$ \\
\hline LDAE & $0.00 \pm 0.00$ & $0.00 \pm 0.00$ & $0.00 \pm 0.00$ & $0.00 \pm 0.00$ & $21.50 \pm 2.12$ & $9.00 \pm 0.00$ & $5.75 \pm 0.63$ & $4.85 \pm 0.07$ \\
\hline LDEE & $0.00 \pm 0.00$ & $0.00 \pm 0.00$ & $0.00 \pm 0.00$ & $0.00 \pm 0.00$ & $20.50 \pm 0.70$ & $10.50 \pm 0.70$ & $5.45 \pm 0.77$ & $4.95 \pm 0.49$ \\
\hline HDAE & $0.00 \pm 0.00$ & $0.00 \pm 0.00$ & $0.00 \pm 0.00$ & $0.00 \pm 0.00$ & $22.00 \pm 1.41$ & $7.50 \pm 0.70$ & $5.00 \pm 0.28$ & $4.80 \pm 0.14$ \\
\hline HDEE & $0.00 \pm 0.00$ & $0.00 \pm 0.00$ & $0.00 \pm 0.00$ & $0.00 \pm 0.00$ & $21.50 \pm 1.33$ & $8.50 \pm 0.70$ & $5.45 \pm 0.49$ & $4.85 \pm 0.21$ \\
\hline \multicolumn{5}{|c|}{ Chloroform fraction } & \multicolumn{4}{|c|}{ N-butanol fraction } \\
\hline $\mathrm{CON}$ & $20.05 \pm 0.75$ & $11.75 \pm 0.95$ & $5.64 \pm 0.47$ & $5.31 \pm 0.40$ & $20.50 \pm 0.58$ & $8.50 \pm 3.11$ & $4.75 \pm 0.72$ & $4.76 \pm 0.74$ \\
\hline SHAM & $21.00 \pm 1.41$ & $11.00 \pm 1.73$ & $5.60 \pm 0.46$ & $5.25 \pm 0.32$ & - & - & - & - \\
\hline LDAE & $27.67 \pm 2.51$ & $11.00 \pm 1.73$ & $5.76 \pm 0.36$ & $5.31 \pm 0.42$ & $25.00 \pm 1.41$ & $9.00 \pm 0.00$ & $5.86 \pm 0.45$ & $5.74 \pm 0.86$ \\
\hline LDEE & $23.67 \pm 0.57$ & $10.33 \pm 0.57$ & $5.55 \pm 0.42$ & $5.19 \pm 0.28$ & $23.00 \pm 1.41$ & $9.50 \pm 0.71$ & $5.69 \pm 0.71$ & $4.60 \pm 0.27$ \\
\hline HDAE & $30.67 \pm 2.08$ & $11.67 \pm 0.57$ & $5.65 \pm 0.49$ & $5.14 \pm 0.18$ & $0.00 \pm 0.00$ & $0.00 \pm 0.00$ & $0.00 \pm 0.00$ & $0.00 \pm 0.00$ \\
\hline HDEE & $22.67 \pm 0.57$ & $12.67 \pm 1.52$ & $5.68 \pm 0.39$ & $5.18 \pm 0.41$ & $0.00 \pm 0.00$ & $0.00 \pm 0.00$ & $0.00 \pm 0.00$ & $0.00 \pm 0.00$ \\
\hline
\end{tabular}

Gray-coloured colums show significant differences from the control group $(\mathrm{P}<0.05)$

Cont: control; LDAE: low dose of aqueous extract; LDEE: low dose of ethanol extract; HDAE: high dose of aqueous extract;

HDEE: high dose of ethanol extract; CRL: crown-rump length.

\section{Acknowledgement}

This study was financially supported by the Vice-Chancellor for Research of the Shiraz University.

\section{References}

1. Adlercreutz H, Bannwart C, Wahala K, Makela T, Brunow G, Hase, T. (1993). Inhibition of human aromatase by mammalian lignans and isoflavonoid phytoestrogens. J Steroid Biochem Mol Biol 44(2): 147-153.

2. Austin CR, Short RV. (1972). Reproduction in mammals: Cycles and seasons.Cambridge University Press; London.

3. Baker ME, Medlock K, Sheehan DM.(1998). Flavonoids inhibit estrogen binding to rat alpha-fetoprotein. Soc Exp Biol Med 217:317-321.

4. Bancroft JD, Stevens A. (1991). Theory and practical of histology techniques. Churchill Living stone;New York.

5. Brun, B. (1990). New ethanol compositions containing anethole. J. Pat. Soc., 75(6), 585-588.

6. Delaquis PJ, Stanich K, Girard B, Mazza G. (2002). Antimicrobial activity of individual and mixed fractions of dill, cilantro, coriander and eucalyptus essential oils. Int J Food Microbiol 74:101-109.

7. Dhar SK. (1995). Anti-fertility activity and hormonal profile of trans-anethole in rats. Ind J Physiol Pharmacol 39(1): 63-67.

8. $\quad$ Duke JA. (2002). Hand book of medicinal herbs (2nd edn).London.

9. Evan WC. (1996). Trease and evans pharmacognosy (14 th edn).Saunders; London.

10. Hosseinzadeh H, Karimi R, Ameri M.2002. Effects of Anethum graveolens L. seed extract on experimental gastric irritation in mice. J BMC Pharmacol 2(1):1-30.

11. Hung H. (2004). Inhibition of estrogen receptor alpha expression and function in MCF-7 cells by kaempferol. cell physiol198(2): 197-208.

12. Kurzer M, Xiz Xu.(1997). Dietary Phytoestrogens. Annu Rev Nutr 17: 353-381. 
Publisher: African Networks on Ethnomedicines

Web page: /http://journals.sfu.ca/africanem/index.php/ajtcam/index

http://dx.doi.org/10.4314/ajtcam.v9i3.6

13. Lopez P, Sanchez C, Batlle R, Nerin C. (2005). Solid- and vapor-phase antimicrobial activities of six essential oils: susceptibility of selected food borne bacterial and fungal strains. J Agric Food Chem 53(17): 6939-6946.

14. Monsefi M, Ghasemi M, Bahaodini A. $\left(2006^{\circ}\right)$. The Effects of (Anethum graveolens L.) on female reproductive system. Phytother Res 20: 865-868.

15. Monsefi M, Ghasemi M, Bahaodini A. (2006b). The effects of Anethum graveolens L. on female reproductive system of rats. Daru 14(3):131-135.

16. NIH (1985) Anonymous Principles of National Institute of Health, revised 1985. NIH Publication, No. 85-23.

17. Nakano Y, Matsunaga H, Saita T, Mori M, Katano M, Okabe H.(1998). Antiproliferative constituents in Umbelliferae plants П. Screening for polyacetylenes in some Umbellifera plants, and isolation of panaxynol and falcaindiol from the root of Heracleum moellendorffii. Biol Pharmacol Bull 21(3): 257-261.

18. Satyanarayana S, Sushruta K, Sarma GS, Srinivas N, Subba Raju GV. (2004). Antioxidant activity of the aqueous extracts of spicy food additives--evaluation and comparison with ascorbic acid in in-vitrosystems. J Herb Pharmacother 4(2): $1-10$.

19. Singh G, Kapoor IPS, Pandey SK, Singh UK, Singh RK. (2001). Studies on essential oils: part 10; Antibacterial activity of volatile oils of some spices. Phytother Res 16: 680-682.

20. Weiss RF. (2001). Weiss's herbal medicine. Thieme Stattgart; New York. 